\title{
PENINGKATAN KOMPETENSI PENGGUNAAN APLIKASI MICROSOFT EXCEL BAGI GURU-GURU SEKOLAH DASAR DI DESA KINTAMANI KABUPATEN BANGLI
}

\author{
N.M.A.E.D. Wirastuti ${ }^{1}$, I.G.A.K.D.D. Hartawan ${ }^{2}$, I.M.A. Suyadnya ${ }^{3}$, dan D.C. \\ Khrisne $^{4}$
}

\begin{abstract}
ABSTRAK
Teknologi Informasi dan Komunikasi (TIK) dapat dikembangkan sebagai salah satu sarana dalam proses pembelajaran dan kegiatan administrasi di sekolah. Guru dituntut untuk menguasai teknologi agar proses pembelajaran lebih inovatif sehingga tidak membosankan. Salah satu penggunaan aplikasi dalam TIK dalam membantu guru-guru dalam pekerjaan yang berhubungan dengan data dan angka adalah Microsoft Excel. Dengan mengggunakan Microsoft Excel guru akan mampu mengolah nilai secara otomatis dan cepat. Pada kegiatan pengabdian ini diberikan penyuluhan dan pelatihan mengenai Microsoft Excel yang bersifat praktis dan aplikatif. Praktis karena peserta mempraktekkan semua teori yang diberikan dan aplikatif artinya pelatihan disertai dengan contoh penggunaan Microsoft Excel untuk kegiatan administrasi sekolah yang sering digunakan. Kegiatan pengabdian ini adalah salah satu kegiatan pendalaman materi dan pengembangan TIK untuk guru-guru sekolah dasar di Desa Kintamani Kabupaten Bangli yang merupakan kelanjutan dari kegiatan pengembangan dan pendampingan ketrampilan TIK yang sudah dilaksanakan sejak tahun 2015.
\end{abstract}

Kata kunci : Angka, Data, Microsoft Excel, Teknologi Informasi dan Komunikasi

\begin{abstract}
Information and Communication Technology (ICT) can be developed to support learning process and administration activities in schools. Teachers are required to be a key master technology so that the learning process is more innovative. One of the use of applications in ICT in helping teachers in work related to data and numbers is Microsoft Excel. Using Microsoft Excel, the teacher will be able to process grades automatically and quickly. In this service, counseling and training on Microsoft Excel that are practical and applicable are provided. Participants were practiced all the theories provided and are applicable, training was accompanied by examples of using Microsoft Excel for school administration activities. This dedication activity is one of the activities to deepen material and ICT development for elementary school teachers in Kintamani Village, Bangli Regency, which is a continuation of ICT skills development and assistance activities that have been carried out since 2015 .
\end{abstract}

Keywords: Numbers, Data, Microsoft Excel, Information and Communication Technology

\section{PENDAHULUAN}

\footnotetext{
${ }^{1}$ Program Studi Teknik Elektro Fakultas Teknik Universitas Udayana, Bali, Indonesia, Email: dewi.wirastuti@unud.ac.id

2 Program Studi Teknik Elektro Fakultas Teknik Universitas Udayana, Bali, Indonesia

${ }^{3}$ Program Studi Teknik Elektro Fakultas Teknik Universitas Udayana, Bali, Indonesia

${ }^{4}$ Program Studi Teknik Elektro Fakultas Teknik Universitas Udayana, Bali, Indonesia
} 
Kewajiban diberlakukannya kurikulum 2013 mulai tahun ajaran 2018/2019 oleh Kementerian Pendidikan dan Kebudayaan (Kemendikbud) mengharuskan guru-guru untuk meningkatkan kompetensinya terutama pada bidang teknologi informasi dan komunikasi (TIK). Salah satu sarana pendukung bagi peningkatan kualitas pendidikan khususnya pada metode pembelajaran adalah TIK. Disamping didukung juga oleh prasarana pendidikan lainnya yaitu gedung, ruang kelas, komputer dan LCD proyektor. TIK dapat dikembangkan sebagai salah satu sarana dalam proses pembelajaran dan kegiatan administrasi di sekolah. Guru dituntut untuk menguasai teknologi agar proses pembelajaran lebih inovatif sehingga tidak membosankan. Kemampuan dasar TIK yang harus dikuasai guru adalah internet, Microsoft Word, Microsoft Excel dan Microsoft PowerPoint.

Internet sebagai sumber informasi yang sangat mudah diperoleh. Oleh karena itu guru sekolah dasar wajib menguasai kemampuan menggunakan internet terutama untuk mencari artikel/materi ajar, menggunakan email dan mendownload. Microsoft Word digunakan untuk mempermudah menyusun administrasi guru. Sedangkan Microsoft Excel digunakan untuk mengolah angka dan data agar dapat diformulasikan dengan cepat. Sehingga guru tidak lagi menggunakan kalkulator mencari rata-rata hasil belajar siswa. Dalam pengolahan data-data lain guru juga akan lebih mudah mengerjakannya. Dengan menggunakan Microsoft Excell tampilan yang dibuat guru dalam mengolah nilai jauh lebih rapi dan baik dari pada dikerjakan manual. Sistem penilaian pada kurikulum 2013 yang tidak mudah, guru harus bisa mengolah angka-angka hingga berbentuk laporan deskripsi atau hasil belajar siswa. Pembelajaran yang interaktif dan inovatif dapat diwujudkan dengan penggunaan Microsoft PowerPoint dalam presentasi materi dan animasi pembelajaran. Sehingga siswa menjadi kreatif dan tidak cepat bosan dalam mengikuti pelajaran.

Pada kegiatan pengabdian ini diberikan pelatihan dan praktik cara menggunakan Microsoft Excel dengan tepat sehingga dapat mempermudah dan membantu administrasi guru dalam mengolah data dan angka. Pada kegiatan pengabdian ini, pelatihan Microsoft Excel menggunakan metode praktis dan aplikatif. Praktis karena peserta mempraktekkan semua teori yang diberikan dan aplikatif artinya pelatihan disertai dengan contoh penggunaan Microsoft Excel untuk kegiatan administrasi sekolah yang sering digunakan guru. Adapun materi pelatihan berupa Mengenal Worksheet dan Operasi Dasar; Mengatur Format Sel dan Layout; Jenis Data, Enter Data dan Operasi Data; Alamat Sel; Fungsi Logika dan Statistik; Fungsi Logika Lanjut dan Sisipan Baris/Kolom; Fungsi Vlook Up; Grafik; Operasi Database.

Adapun tujuan dari kegiatan pengabdian kepada masyarakat ini adalah: 1) untuk memberikan pengetahuan kepada guru-guru sekolah dasar di Desa Kintamani tentang pentingnya penggunaan aplikasi Microsoft Office dan Internet untuk mempermudah guru-guru dalam membantu tugastugas guru di sekolah; 2) Untuk memberikan pengetahuan dan ketrampilan kepada guru-guru sekolah dasar di Desa Kintamani tentang cara menggunakan aplikasi Microsoft Excel untuk menyelesaikan tugas guru di sekolah yang berkaitan dengan data dan angka; 3) Untuk mengevaluasi guru-guru dalam menggunakan Microsoft Excel menggunakan metode Test Komprehensif.

\section{METODE PELAKSANAAN}

Metode pelaksanaan dalam kegiatan pengabdian kepada masyarakat ini adalah dengan menggunakan: 
1. Metode wawancara dan observasi

Melakukan identifikasi masalah yang berhubungan dengan mengenai kegiatan/tugas yang dikerjakan guru-guru di sekolah yang bisa dibantu dengan menggunakan kemajuan teknologi TIK. Mengumpulkan data mengenai tugas-tugas yang harus diselesaikan oleh guru yang berhubungan dengan angka dan data. Langkah ini dilakukan dengan wawancara dengan pihak kepala sekolah dan guru-guru. Untuk perangkat komputer yang digunakan untuk pelatihan dan praktikum akan disediakan oleh masing-masing peserta pelatihan.

2. Metode pelatihan dan praktik

Melakukan pemaparan secara komprehensif mengenai penggunaan kemajuan teknologi TIK khususnya apliasi Microsoft Office dan Internet dalam menunjang kegiatan dan tugas-tugas guru di sekolah. Kemudian diberikan pemaparan teori aplikasi Microsoft Excel yang dilengkapi dengan contoh penyelesaian masalah sederhana menggunakan Microsoft Excel. Pelatihan dan praktik penyelesaian masalah yang berkaitan dengan tugas-tugas guru yang berkaitan dengan data dan angka juga diberikan saat pelatihan. Kegiatan pelatihan ini dilaksanakan selama dua kali tatap muka. Kegiatan evaluasi kemampuan guru dalam menggunakan Excel dan evaluasi kegiatan pengabdian dilaksanakan dalam satu hari.

3. Metode pemantauan dan diskusi pemecahan masalah

Pemantauan dan diskusi dilaksanakan pada saat pelaksanaan pelatihan dilaksanakan. Diskusi ini ditujukan untuk memberi pendampingan saat pelatihan dan menjawab permasalahan yang ada disetiap materi yang disampaikan. Sedang pemantauan dimaksudkan untuk mengetahui tingkat kemampuan guru, sehingga materi yang disampaikan menyesuaikan tingkat penyerapan peserta (guru).

4. Metode evaluasi

a. Evaluasi Hasil

Proses evaluasi keberhasilan penyampaian materi pelatihan dapat dilihat dari adanya peningkatan wawasan guru-guru dalam bagaimana teknologi TIK dalam menunjang kegiatan pembelajaran dan mempermudah tugas administrasi guru di sekolah. Keberhasilan kegiatan juga dapat dilihat dari antusias peserta dalam mengikuti pelatihan yang ditunjukkan dengan diskusi yang menarik. Kemampuan guru dalam menggunakan aplikasi Microsoft Excel dalam menyelesaikan tugas administrasi di sekolah juga akan menjadi salah satu indikator keberhasilan kegiatan pelatihan.

b. Evaluasi kegiatan

Hal-hal yang perlu diperhatikan dalam melakukan evaluasi adalah:

- Jumlah guru yang hadir pada saat diadakan kegiatan pengabdian.

- Evaluasi dilakukan pada akhir kegiatan dengan menyediakan waktu untuk menanyakan hal-hal yang belum jelas untuk kemudian diberikan penjelasan sampai semua peserta memahami.

- Hasil kuesioner.

- Respon kepala sekolah dan guru-guru terhadap kegiatan pengabdian ini.

5. Metode pelaporan hasil pelatihan

Pelaporan hasil dilaksanakan setelah semua kegiatan terealiasasi, kemudian dianalisa pencapaian terhadap tujuan, faktor pendukung dan faktor penghambat dalam pelaksanaan kegiatan pengabdian ini. 


\section{HASIL DAN PEMBAHASAN}

\subsection{Observasi dan Koordinasi Lapangan}

Sebelum melakukan kegiatan pelatihan "Workshop dan Pelatihan Penggunaan Aplikasi Microsoft untuk Pengolah Data dan Angka bagi Guru-Guru Sekolah Dasar di Kecamatan Kintamani Kabupaten Bangli" dilaksanakan observasi langsung ke lapangan. Observasi ke lapangan dilaksanakan pada hari Jumat, 5 Juli 2019, yang bertujuan untuk menjelaskan maksud dan tujuan serta permohonan kerja sama pihak sekolah dalam hal ini Kepala Sekolah SDN 2 Kintamani dalam kegiatan pengabdian kepada masyarakat, yang kemudian ditindaklanjuti dengan mengirimkan surat resmi permohonan ijin untuk melakukan kegiatan pengabdian yang akan mengambil lokasi di SDN 2 Kintamani.

Pada pertemuan ini juga didiskusikan tentang mekanisme kegiatan, yaitu: peserta pelatihan, perangkat dan materi yang harus dipersiapkan oleh peserta, materi yang akan diberikan oleh pengabdi, dan proses evaluasi kegiatan dengan melombakan hasil karya dari peserta pelatihan. Kegiatan ini merupakan kelanjutan dari kegiatan sebelunya berkenaan dengan pendampingan peningkatan kemampuan teknologi informasi bagi guru-guru sekolah dasar di Desa Kintamani yang telah dilaksanakan pada sejak tahun 2015.

Dari hasil observasi diperoleh informasi bahwa ketersediaan perangkat komputer di SD Imbas Gugus 1 dan jaringan wireless adalah masih sama seperti tahun lalu, yaitu: SDN-SDN tersebut pada umumnya belum mempunyai ruang komputer, dan hanya mempunyai beberapa komputer yang dipergunakan untuk kegiatan administrasi sekolah dan beberapa laptop untuk kegiatan guruguru. Ada beberapa guru sudah memiliki laptop dan modem wireless sendiri-sendiri. Bapak Kepala Sekolah sangat antusias dengan adanya kesempatan baik ini, karena sasaran SDN Imbas adalah memang untuk meningkatkan kemampuan TI guru-gurunya. Jadi dengan adanya kegiatan ini beliau berharap sangat membantu guru-guru dalam menambah wawasan dan kemampuan TInya termasuk dalam hal penggunaan Microsft Excel yang lebih professional dalam membantu dan mempermudah guru-guru dalam melaksanakan tugas-tugasnya di sekolah.

Dilakukan kembali pertemuan kedua dengan Kepala Sekolah SDN 2 Kintamani pada hari Jumat 29 Juli 2019 untuk memantapkan ruangan untuk tempat pelatihan berkenaan dengan fasilitas akses Internet, komputer/laptop, kapasitas ruang pelatihan, jumlah peserta dan materi pelatihan. Pada pertemuan tersebut disepakati waktu pelatihan adalah di akhir bulan Agustus dimana tepatnya akan dikomunikasikan kembali via telepon. Pada hari Kamis, 30 Juli 2019, dikirim surat permohonan kegiatan pengabdian kepada masyarakat "Workshop dan Pelatihan Penggunaan Aplikasi Microsoft untuk Pengolah Data dan Angka bagi Guru-Guru Sekolah Dasar di Kecamatan Kintamani Kabupaten Bangli”, yang ditujukan ke Kepala SDN 2 Kintamani.

\subsection{Penyusunan Materi Pelatihan}

Dilakukan lima kali pertemuan untuk membahas dan mengumpulan referensi/materi pelatihan, termasuk software yang akan diinstall pada laptop masing-masing peserta pelatihan. Kemudian materi dibuat dalam bentuk panduan dan file presentsai. Adapun materi yang akan disampaikan adalah

- Mengenal Worksheet dan Operasi Dasar;

- Mengatur Format Sel dan Layout;

- Jenis Data, Enter Data dan Operasi Data; 
- $\quad$ Alamat Sel;

- Fungsi Logika dan Statistik;

- Fungsi Logika Lanjut dan Sisipan Baris/Kolom;

- $\quad$ Fungsi Vlook Up; Grafik; Operasi Database

\subsection{Pelaksanan Kegiatan}

Setelah beberapa kali penundaan untuk mencari waktu yang tepat dipihak sekolah dan tim pengabdi, akhirnya disepakati kegiatan Pengabdian kepada Masyarakat yang dikemas dalam 4 kali interaksi. Interaksi pertama dan kedua dengan membuat pembelajaran Microsoft Excel secara daring. Jadi materi-materinya di bagikan secari daring. Kemudian interaksi ketiga adalah dilaksanakan pada hari Rabu, 27 Oktober 2019, mulai pukul 09.00 Wita dan bertempat di SDN 2 Kintamani, Kecamatan Kintamani, Kabupaten Bangli. Kegaitan berupa Workshop dan Pelatihan mengambil tema "Workshop dan Pelatihan Penggunaan Aplikasi Microsoft untuk Pengolah Data dan Angka bagi Guru-Guru Sekolah Dasar di Kecamatan Kintamani Kabupaten Bangli”. Kemudian interaksi terakhir adalah secara daring dengan memberikan soal-soalnya harus dijawab secara daring juga.

Kegiatan "Workshop dan Pelatihan Penggunaan Aplikasi Microsoft untuk Pengolah Data dan Angka bagi Guru-Guru Sekolah Dasar di Kecamatan Kintamani Kabupaten Bangli" diikuti oleh 28 peserta dari 36 orang yang mendaftar. Tidak semua diterima karena mempertimbangkan luaran dan keseriusan peserta sehingga dilakukan proses seleksi.

- Sesi pertama dihantarkan oleh Bapak IGAK Diafari Djuni Hartawan, ST., MT. dan Ibu Ni Made Ary Esta Dewi Wirastuti, ST., MSc., PhD., menjelaskan tentang Mengenal Worksheet dan Operasi Dasar; Mengatur Format Sel dan Layout. Diberikan beberapa latihan soal. Sesi kedua diberikan oleh Bapak I Made Arsa Suyadnya, ST., MEng. Materi yang diberikan adalah tentang Jenis Data, Enter Data dan Operasi Data; Alamat Sel, diberikan juga beberapa contoh soal. Diakhir kegiatan sesi kedua diberikan kegiatan quiz dengan menggunaan aplikasi www.kahoot.com, dan diakhir quiz diperoleh tiga peserta dengan nilai tertinggi diberikan reward berupa USB Flashdisk. Contoh hasil penggunaan Kahoot seperti pada Gambar 1. 


\begin{tabular}{|c|c|c|c|c|c|c|}
\hline \multicolumn{7}{|c|}{ Quizz Microsoft Excel } \\
\hline 10 Quiz & \multirow{2}{*}{\multicolumn{6}{|c|}{$\begin{array}{l}\text { Perintah untuk menggabungkan beberapa sel yang berdekatan dan data yang akan diformat rata } \\
\text { tengah adalah...... } \\
\text { wers } \quad \text { Merge and Center }\end{array}$}} \\
\hline \multirow{2}{*}{\multicolumn{2}{|c|}{$\begin{array}{l}\text { Correct answers } \\
\text { Players correct }(\%)\end{array}$}} & & & & & \\
\hline & & \multicolumn{5}{|c|}{$68.00 \%$} \\
\hline \multicolumn{2}{|c|}{ Question duration } & \multicolumn{5}{|c|}{20 seconds } \\
\hline \multicolumn{7}{|c|}{ Answer Summary } \\
\hline \multicolumn{2}{|c|}{ Answer options } & $\Delta$ & Center & Align Left & $\begin{array}{l}\text { Merge and } \\
\text { Center }\end{array}$ & Align Right \\
\hline \multicolumn{2}{|c|}{ Is answer correct? } & \multicolumn{2}{|l|}{$x$} & $x$ & 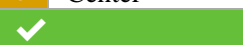 & $x$ \\
\hline \multicolumn{2}{|c|}{$\begin{array}{l}\text { Number of answers } \\
\text { received }\end{array}$} & \multicolumn{2}{|l|}{2} & 0 & 17 & 0 \\
\hline \multicolumn{2}{|c|}{$\begin{array}{l}\text { Average time taken to } \\
\text { answer (seconds) }\end{array}$} & \multicolumn{2}{|l|}{5.80} & 0.00 & 6.33 & 0.00 \\
\hline \multicolumn{7}{|c|}{ Answer Details } \\
\hline \multicolumn{2}{|c|}{ Players } & \multicolumn{2}{|c|}{ Answer } & Score (points) & $\begin{array}{l}\text { Current Total } \\
\text { Score (points) }\end{array}$ & $\begin{array}{ll}\begin{array}{l}\text { Answer } \\
\text { (seconds) }\end{array} & \text { time }\end{array}$ \\
\hline \multicolumn{2}{|l|}{83701} & \multicolumn{2}{|l|}{$x$} & 0 & 0 & 20 \\
\hline Andrayug & & $x$ & & 0 & 0 & 20 \\
\hline Chiptanan & & $x$ & Center & 0 & 5661 & 3.9 \\
\hline Dewa Ged & Eka & & $\begin{array}{l}\text { Merge and } \\
\text { Center }\end{array}$ & 823 & 7634 & 7.1 \\
\hline Duman & & $x$ & & 0 & 0 & 20 \\
\hline Gung Asti & & $\checkmark$ & $\begin{array}{l}\text { Merge and } \\
\text { Center }\end{array}$ & 913 & 7584 & 3.5 \\
\hline Gung mus & & $\checkmark$ & $\begin{array}{l}\text { Merge and } \\
\text { Center }\end{array}$ & 1000 & 3745 & 4 \\
\hline Gung nust & & $x$ & & 0 & 0 & 20 \\
\hline I Gede Su & tika & $\checkmark$ & $\begin{array}{l}\text { Merge and } \\
\text { Center }\end{array}$ & 893 & 4359 & 4.3 \\
\hline Luh & & $\checkmark$ & $\begin{array}{l}\text { Merge and } \\
\text { Center }\end{array}$ & 873 & 1603 & 5.1 \\
\hline Mahardika & & $\checkmark$ & $\begin{array}{l}\text { Merge and } \\
\text { Center }\end{array}$ & 738 & 2321 & 10.5 \\
\hline Rumada & & $\checkmark$ & $\begin{array}{l}\text { Merge and } \\
\text { Center }\end{array}$ & 1150 & 8681 & 10 \\
\hline SATRIA & & $x$ & Center & 0 & 6012 & 7.7 \\
\hline Sentana & & $\checkmark$ & $\begin{array}{l}\text { Merge and } \\
\text { Center }\end{array}$ & 1030 & 6260 & 2.8 \\
\hline Somantara & & $\checkmark$ & $\begin{array}{l}\text { Merge and } \\
\text { Center }\end{array}$ & 875 & 6372 & 9 \\
\hline Soni & & $x$ & & 0 & 0 & 20 \\
\hline Soni $\mathrm{m}$ & & $\checkmark$ & $\begin{array}{l}\text { Merge and } \\
\text { Center }\end{array}$ & 833 & 1721 & 6.7 \\
\hline Sudiarpa & & $x$ & & 0 & 0 & 20 \\
\hline Suwedana & & $\checkmark$ & $\begin{array}{l}\text { Merge and } \\
\text { Center }\end{array}$ & 1413 & 12173 & 3.5 \\
\hline budiarta & & $\checkmark$ & $\begin{array}{l}\text { Merge and } \\
\text { Center }\end{array}$ & 840 & 4629 & 6.4 \\
\hline desi & & $\checkmark$ & $\begin{array}{l}\text { Merge and } \\
\text { Center }\end{array}$ & 1230 & 6381 & 6.8 \\
\hline eko susilo & & $\checkmark$ & $\begin{array}{l}\text { Merge and } \\
\text { Center }\end{array}$ & 1400 & 8679 & 4 \\
\hline gde & & $\checkmark$ & $\begin{array}{l}\text { Merge and } \\
\text { Center }\end{array}$ & 905 & 6378 & 11.8 \\
\hline luh sukerti & & $\checkmark$ & $\begin{array}{l}\text { Merge and } \\
\text { Center }\end{array}$ & 843 & 2183 & 6.3 \\
\hline sandi & & $\checkmark$ & $\begin{array}{l}\text { Merge and } \\
\text { Center }\end{array}$ & 855 & 5056 & 5.8 \\
\hline
\end{tabular}

Gambar 1. Hasil quiz dengan menggunakan aplikasi Kahoot.com 
- Sesi ketiga diberikan oleh Bapak Duman care Khrisne, ST, MT. Materi yang diberikan adalah tentang Fungsi Logika dan Statistik; Fungsi Logika Lanjut dan Sisipan Baris/Kolom; Fungsi Vlook Up; Grafik; Operasi Database. Diakhir kegiatan diberikan 3 pertanyaan yang harus dijawab dengan mendemokan caranya dihadapan narasumber dan peserta lainnya. Untuk materi dan contoh soal bisa dilihat di Lampiran 3.

Foto-foto kegiatan dapat dilihat pada Gambar 2 dan Gambar 3.

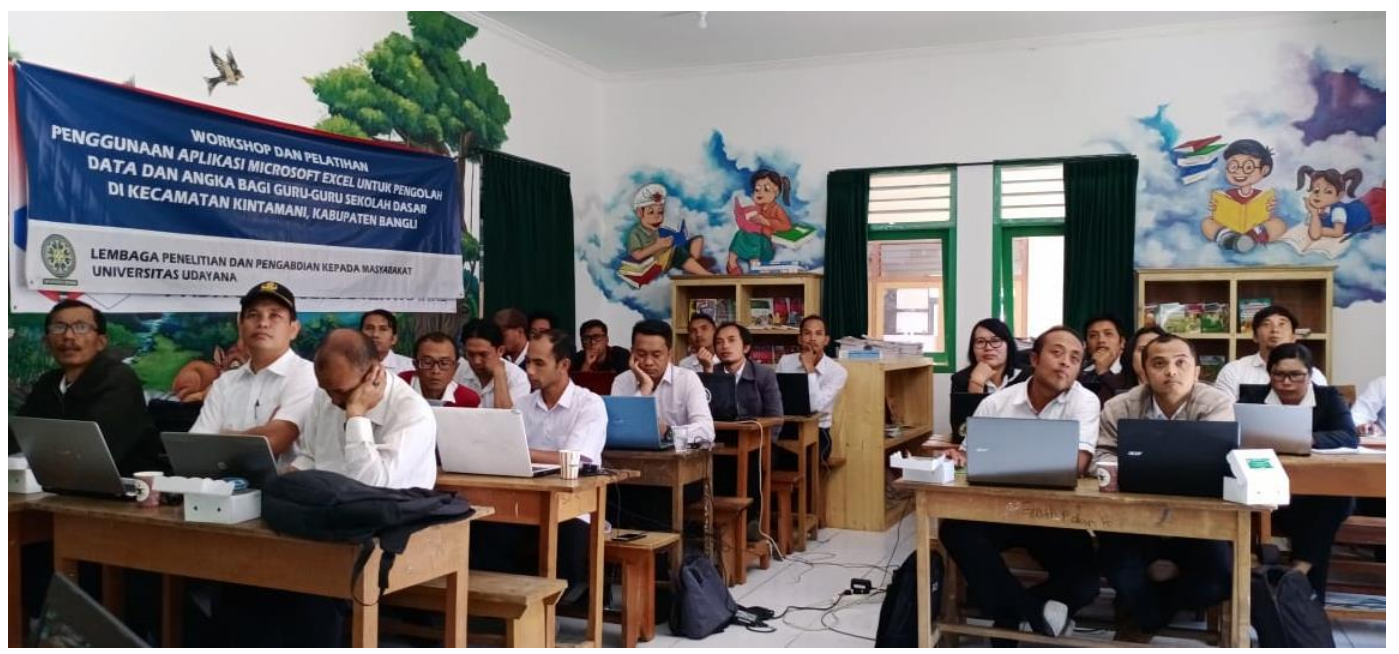

Gambar 2. Antusias peserta mendengarkan dan mencoba aplikasi Microsoft Excel sesuai dengan intruksi narasumber

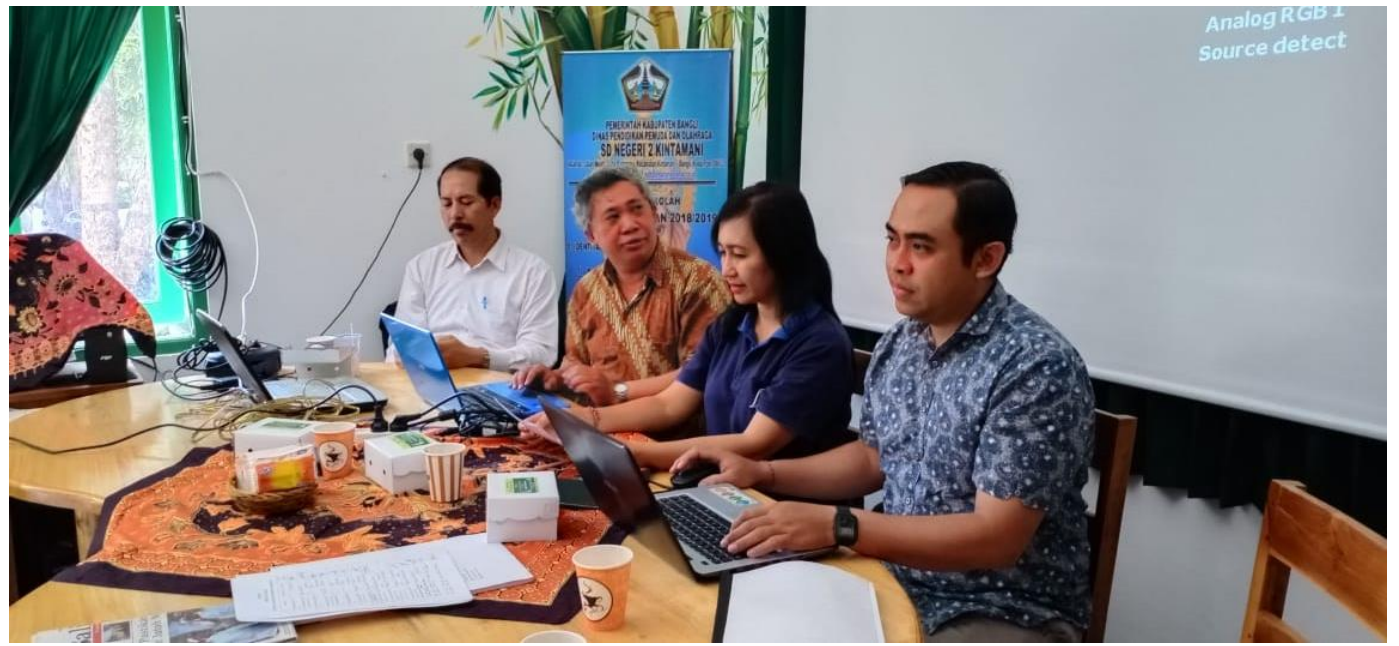

Gambar 3. Tim pengabdi Unud dan Ketua Pengawas Pendidikan Kabupaten Bangli

\section{KESIMPULAN}

Faktor-faktor yang mendukung terlaksananya kegiatan pengabdian pada masyarakat ini adalah adanya dukungan dana dari LPPM UNUD, dukungan dari Program Studi Teknik Elektro Unud, dan besarnya motivasi, minat dan antusiasme peserta selama kegiatan, sehingga kegiatan berlangsung dengan lancar dan efektif. Sedangkan faktor penghambatnya adalah keterbatasan waktu penyuluhan dan pelatihan, dan kurangnya fasilitas komputer dan sambungan internet. Indikator keberhasilan yang telah dicapai dalam penyuluhan dan pelatihan ini dapat dilihat dari pencapaian kompetensi guru- guru yang dilihat dari pengamatan selama proses demo dan pelatihan, 
yaitu: peserta mengerti cara membuka aplikasi Microsoft Excel dan dapat menyelesaikan latihanlatihan soal yang diberikan oleh narasumber dan lebih dari $90 \%$ berhasil menjawab quiz dengan benar.

\section{UCAPAN TERIMA KASIH}

Penulis mengucapkan terima kasih kepada LPPM Universitas Udayana yang telah memberikan dukungan dana sehingga pelaksanaan kegiatan ini dapat berjalan sesuai rencana. Ucapan terima kasih pula kepada semua pihak yang telah mendukung kegiatan ini.

\section{DAFTAR PUSTAKA}

Borg, W. R., \& Gall, M. D. (2003). Educational research: An introduction (7th ed). New York: Longman.

Dick, W., Carey, L., \& Carey, J.O. (2005). The systematic design of instruction. (6ed). New York: Person.

Khvilon, Evgueni, Patru, Mariana. (2002). Information and Communication Technologies in Teacher Education. Division of Higher Education UNESCO.

Pardosi, M. (2003). Pengenalan Internet. Bandung: P.T. Pradnya Paramita.

Shenia A. \& Irwan Rouf. (2011). Buku Pintar Menguasai Microsoft Excel untuk Pemula. Jakarta Selatan: PT. TransMedia. 